AIDS and Behavior, vol. 11, núm. 4, 2006, pp. 641-645.

\title{
Some Data-Driven Reflections on Priorities in AIDS Network Research.
}

Friedman, Samuel, Bolyard, Melissa, Mateu Gelabert, Pedro, Goltzman, Paula, Pawlowicz, María Pía, Zunino Singh, Dhan, Touze, Graciela, Rossi, Diana, Maslow, Carey, Sandoval, Milagros y Flom, Peter.

Cita:

Friedman, Samuel, Bolyard, Melissa, Mateu Gelabert, Pedro, Goltzman, Paula, Pawlowicz, María Pía, Zunino Singh, Dhan, Touze, Graciela, Rossi, Diana, Maslow, Carey, Sandoval, Milagros y Flom, Peter (2006). Some Data-Driven Reflections on Priorities in AIDS Network Research. AIDS and Behavior, 11 (4), 641-645.

Dirección estable: https://www.aacademica.org/maria.pia.pawlowicz/88 ARK: https://n2t.net/ark:/13683/pgaP/dkd

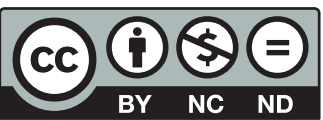




\title{
Some Data-Driven Reflections on Priorities in AIDS Network Research
}

\author{
Samuel R. Friedman · Melissa Bolyard · \\ Pedro Mateu-Gelabert · Paula Goltzman · \\ Maria Pia Pawlowicz · Dhan Zunino Singh • \\ Graciela Touze · Diana Rossi - Carey Maslow • \\ Milagros Sandoval · Peter L. Flom
}

(C) Springer Science+Business Media, Inc. 2006

\begin{abstract}
Risk networks can transmit HIV or other infections; social networks can transmit social influence and thus help shape norms and behaviors. This primarily-theoretical paper starts with a review of network concepts, and then presents data from a New York network study to study patterns of sexual and injection linkages among IDUs and other drug users and nonusers, men who have sex with men, women who have sex with women, other men and other women in a high-risk community and the distribution of HIV, sex at group sex events, and health intravention behaviors in this network. It then discusses how risk network microstructures might influence HIV epidemics and urban vulnerability to epidemics; what social and other forces (such as "Big Events" like wars or ecological disasters) might shape networks and their associated norms, intraventions, practices and behaviors; and how network theory and research have and may continue to contribute to developing interventions against HIV epidemics.
\end{abstract}

Keywords Social networks $\cdot$ Sex $\cdot$ Drugs $\cdot$ HIV Norms $\cdot$ Risk $\cdot$ Vulnerability $\cdot$ Wars $\cdot$ Transitions · Interventions $\cdot$ Gays $\cdot$ Lesbians · Injection drug users

S. R. Friedman $(\bowtie) \cdot$ M. Bolyard · P. Mateu-Gelabert · C. Maslow · M. Sandoval · P. L. Flom

National Development and Research Institutes, Inc., 71

West 23rd Street, 8th floor, New York, NY 10010, USA

e-mail: friedman@ndri.org

P. Goltzman · M. P. Pawlowicz · D. Z. Singh ·

G. Touze $\cdot$ D. Rossi

Intercambios Civil Association, Buenos Aires, Argentina

\section{Introduction}

As has become increasingly understood by people engaged in HIV/AIDS research, prevention and care, both risk behaviors and the probability of being or becoming infected with HIV depend upon social relationships and risk relationships (i.e., sexual or injection relationships). The ways in which these relationships affect risk behaviors and probabilities of being or becoming infected have been studied using social network approaches.

In this paper, we first present some network concepts; then, discuss the methods we used in a study of networks in the Bushwick section of Brooklyn, NY; use these data and the literature to present some results and musings about networks; and finally discuss the implications of network approaches for interventions around HIV/AIDS.

\section{Some Network Concepts}

Usually, HIV behavioral research focuses on a given person, "Ego." However, as we all know, Ego has social relationships of a given kind with various Alters. Ego's relationships (and Alters) that are socially meaningful can be viewed as Ego's "egocentric" or "personal" social network. If we extend this outwards to include all of the social relationships of Ego's social network members, and then further on yet to include their social networks, and so on, we define the "connected component" of the sociometric social network to which Ego belongs. (In such a connected component, there is at least one path that connects any two members.) Some community members may not be in this connected component; thus, if we do a network 
survey in a community we are likely to find a number of separate connected components; some of which might be measured as having only one member if a participant either has no social relationships or fails to report them. Such a set of connected components would be a "community social network."

Ego may have sex with or inject drugs with some Alters. These relationships and these Alters are Ego's "egocentric risk network". Although most risk relationships are also social relationships, it is possible that some might lack any socially-meaningful communication in some settings. As with social networks, we can define sociometric and community risk networks.

To illustrate these concepts, Fig. 1 presents a community risk network from the study described below.

The Networks, Norms and HIV Risk Among Youth Project

Although this paper is primarily theoretical, it does use some data both to illustrate points that are made and also as a base from which to muse about what it would be nice to know. Thus, we here present an abbreviated discussion of the methods used in the Networks, Norms and HIV Risk among Youth (NNAHRAY) project.

NNAHRAY aimed to study the sexual network connections that link injection drug users (IDUs) to young adults (aged 18-24) in a high-risk neighborhood. It did this by recruiting a sample of IDUs in the
Bushwick neighborhood of Brooklyn and tracing their injection and sexual networks, and also by recruiting a somewhat population-representative sample of young adults in this neighborhood and then recruiting their sexual network members. We thus recruited index cases who met these criteria (IDUs or part of the representative sample of young adults) and then recruited their risk network members, and their network members' networks, and so on.

\section{Recruiting the Index Cases}

Population-representative index cases were recruited in one of two ways: 25 participants had been included in a population-representative sample of Bushwick youth during a previous study (see Flom et al., 2001; Friedman et al., 2001; Friedman et al., 2002a; Friedman et al., 2002b; Friedman et al., 2002c; Friedman et al., 2003a). In addition, 41 others were members of households targeted during that study who were too young to participate at that time, but who were currently 18 or older.

The (non-representative) IDU index cases included four IDUs who were members of a population of IDUs specifically targeted during that earlier study; 19 IDU "walk-ins" who met study criteria; and 16 IDU recruited by project staff in known drug purchasing venues, at shooting galleries, or at needle exchanges in Bushwick. In addition, late in the study, seven index
Fig. 1 HIV Positive by Gender/Sexuality (MSM = up triangle, $\mathrm{WSW}=$ down triangle, other female $=$ circle, other male $=$ square) by Hardest Drug Use Ever (from dark red to light pink: IDU, Crack, NI Heroin or Cocaine; blue $=$ other) by Link Type (sex $=$ yellow line, IDU $=$ red, sex and IDU = blue)

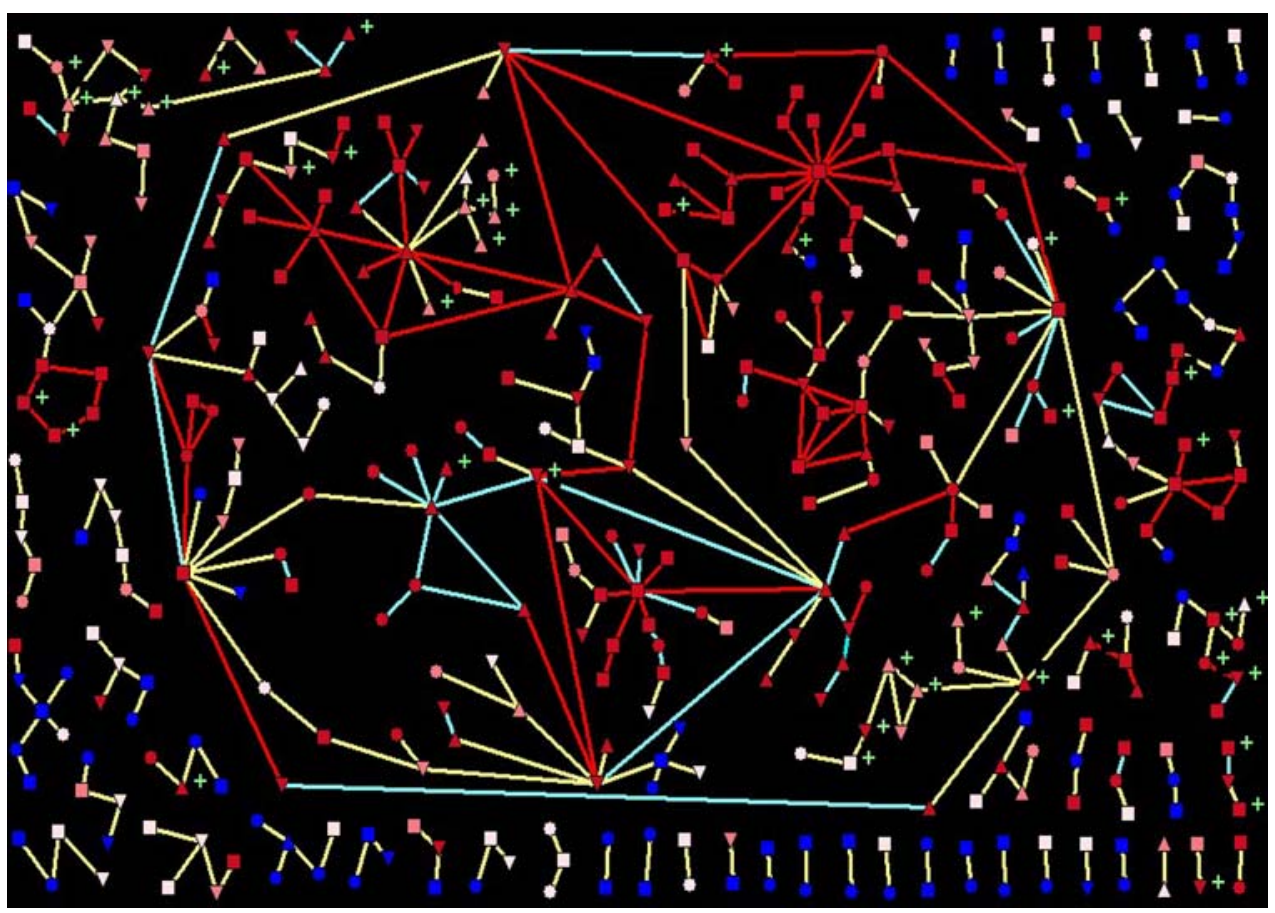


participants were recruited because of their known involvement in a local gay sex party scene.

\section{Recruiting the Risk Networks of the Index Cases}

Through a risk-network tracing process that involved participants bringing their partners in to be interviewed, or giving them a coupon to be redeemed, or our staff locating the partner and recruiting them, 353 additional participants were directly or indirectly linked to one or more of the total of 112 index cases. Participants were considered to be "linked" if one named the other as someone with whom, during the prior 3 months, they had a) injected drugs, b) had sex, and/or c) attended a group sex event. Eligibility requirements included being at least 18 years of age and, for index cases, residing in Bushwick. IDU index cases had to have injected drugs within the prior 3 months, and have visible track marks and/or provide other evidence, during detailed verbal questioning, of having injected during the prior 3 months. In all then, 465 participants were recruited.

Index participants were asked, during the course of the interview, to name up to 10 individuals with whom they had had sex during the prior 3 months, and up to two individuals with whom they had attended a group-sex event during the same time period. (This was increased to eight late in the project when we started recruiting attendees at MSM group sex parties and their networks). In addition, IDU participants were asked to name up to five individuals with whom they had injected during the prior 3 months. The network sampling began by recruiting these named individuals up to a limit of 10 sex partners, five IDU partners, and two group sex attendance partners. In practice, we rarely reached these limits: only 36 , i.e., $8 \%$ of participants, reported sex with more than 10 partners in the last 3 months; and 25 - or $16 \%$ of current IDUs-reported injection with more than five partners in the last 3 months. Successfully recruited links were interviewed as well, and their partners were recruited also. For any given index participant, we limited the number of sex partner, group sex attendance partner and injection partner steps to three (that is, we would recruit the partner of the partner of the partner of the index case). In addition, for each IDU recruited as a link of an index case, we would recruit their sex partners (and group sex attendance partners) and the sex partners (and group sex attendance partners) of these partners. After we reached our sample goal of 200 IDUs, we no longer recruited known injectors.

\section{The Interview}

After providing informed consent, all participants were administered a structured, face-to-face interview in a confidential setting. Interviews lasted an average of $57 \mathrm{~min}(S D=26$; range 19-268 $\mathrm{min})$, and covered sociodemographic descriptors, drug use, sexual and drug risk behaviors engaged in, size and composition of sexual and drug networks, perceived levels of social support and burden, experiences with discrimination, peer norms, participants' own norms, measures of community activism, and measures of health activism. The interview also collected partner-specific locator information, as well as other information about each partner and about activities in which the participant and the partners had engaged together, for everyone they reported having had sex with, injected drugs with, or attended a group sex event with, in the prior 3 months.

\section{Biological Assessments}

After obtaining separate informed consent, $10 \mathrm{ml}$ of blood was collected in a serum separator tube; $10 \mathrm{ml}$ of urine were also collected. They were tested at BioReference Laboratories (Elmwood Park, NJ) for antiHIV; anti-HCV and HBV (core antibody, surface antibody and surface antigen) (all by VITROS by Ortho-Clinical Diagnostics); type-specific (FOCUS) anti-HSV-1 and anti-HSV-2; syphilis (RPR and TPPA), chlamydia (BDProbeTec Amplified DNA assay), and gonorrhea (BDProbeTec Amplified DNA assay). HBV status was defined using standard definitions: Participants positive for surface antibody and negative for surface antigen and core antibody were classified "immunized"; others positive for surface antigen or core antibody were classified "exposed".

On-site urinalysis for drug metabolites (amphetamines, cocaine, marijuana and heroin) was done, using OnTrak "TesTcup" (Roche Diagnostic Systems, Indianapolis, IN) to detect: recent marijuana use (in the last 10 days); heroin use (in the last 2 to 3 days); cocaine use (in the last 2 to 3 days); and amphetamine use (in the last 2 to 4 days).

\section{Limitations}

Like all community network surveys, this study was subject to limitations due to poor recall of whom one had engaged in relevant interactions with during the last 3 months, possible deliberate failure to report some links, failure on our part to match some people 
with partners, and the standard inaccuracy of all forms of questionnaire data.

\section{Findings and Musings}

Among 465 participants, $71 \%$ were Latino/a, 20\% African-American and 7\% White, and 3\% "other." $15 \%$ were men who have sex with men, $43 \%$ other men, $17 \%$ women who have sex with women, and $25 \%$ other women. $43 \%$ had ever injected drugs; $15 \%$ had smoked crack but never injected drugs; $18 \%$ had never injected or used crack, but had used heroin or other cocaine; and $25 \%$ had never used any of these drugs. Of the total, $32 \%$ of women and $21 \%$ of men had traded sex for money or goods in the last 12 months.

Figure 1 provides a network diagram of those participants who were linked to at least one other participant in our study. Not included in this diagram are 53 participants who could not be linked to any other participants. This is because their sex or injection partners were not successfully recruited (if they reported on having partners-nine reported no sex partners) and because they were also not identifiably named as a sex or injection partner by any other participants. Of these 53 participants, 12 were IDUs, 4 crack smokers, 12 other non-injection users of heroin or cocaine, and 25 other. Fourteen were female, 39 male. Four ( $8 \%)$ were HIV-positive, $9(17 \%)$ hepatitis C positive, 16 (31\%) herpes-2 positive, and 7 (14\%) chlamydia positive.

Several things leap out at us from Fig. 1. First, the diagram has a very large connected component of 206 participants. It also contains smaller components of 22 , 15,13 , and 8 members; 2 of 7 members; 1 of 6 members; 6 of 5 members each; 3 of 4 members; 10 of 3 members; and 28 dyads. Second, there are clearly many injectors in the sample who are MSM or WSW, and they often are linked (sexually or through injection) to opposite-sex as well as to same-sex IDUs. They also have many sexual linkages to non-IDUs of the same sex and of the opposite sex. Many WSW are linked sexually and/or through injection to MSM; this is congruent with findings that WSW IDUs, at least, are at very high risk for HIV (Friedman, Curtis, Neaigus, Jose, \& Des Jarlais, 1999a; Friedman et al., 1999b; Friedman et al., 2003b; Young, Friedman, Case, Asencio, \& Clatts, 2000). Third, HIV in this network is concentrated heavily among men who have sex with men and their sex partners. HIV prevalence rates among other injectors are much lower than they would have been if this study had been conducted in the early 1990s or before or than they were in an earlier network study of IDUs that we conducted in Bushwick in the early 1990s (Friedman et al., 1999a), when about half of New York City IDUs were infected; this decline reflects the success in syringe exchange in reducing new infections among IDUs plus the sad reality of many deaths among infected IDUs (Des Jarlais et al., 2000).

\section{Risk Networks and Vulnerability}

A considerable literature suggests that some network characteristics make a network more vulnerable to the spread of viruses. One of these is concurrency, which refers to the overall extent to which individuals in a sexual or injection network have relationships that are concurrent (that is, co-existing over a given time interval) rather than serial (that is, sequential). Thinking conceptually, high concurrency means that the virus can spread from a newly-infected individual to any of several partners, and then spread from those partners to their (several) partners, and thus can spread rapidly through a network; whereas if all relationships are serial, then if person A gets infected by person $\mathrm{X}$, the virus can spread from A to B only after the relationship with $\mathrm{X}$ ends. Concurrency has been shown to be associated with the speed and extent of transmission of infections both in mathematical models and in empirical studies (Gorbach, Drumright \& Holmes, 2005; Kretzschmar \& Morris, 1996; Manhart, Aral, Holmes, \& Foxman, 2002; Potterat et al., 1999a).

Friedman et al. (2000) have suggested that network topologies and dynamics can affect the epidemic curves of HIV and perhaps other epidemics. (Epidemic curves are graphs of infection rates over time.) They make a fairly complicated argument. Basically, what they suggest relies upon the finding that people with HIV are much more infectious during the period of primary infection after they are first infected with the virus than they are during the ensuing long latency period during which their antibody response limits the number of viral particles in their blood, semen and/or vaginal secretions. This makes it possible for those seropositives who have already entered the latency period to function as "firewalls" in risk networks such that the entry of a new case of HIV into the network (with its attendant high-viral load) cannot lead to rapid and widespread further transmission because viruses that are transmitted enter into "firewall" members with their antibodies already developed.

Potterat and his colleagues have suggested that cyclic microstructures facilitate epidemic spread of HIV and other sexually transmitted (or blood-borne) infections more than do dendritic (tree-like) structures (Potterat \& Rothenberg, 1999b; Potterat et al., 2002, see Fig. 2). In cyclic microstructures, the number of paths by which a 


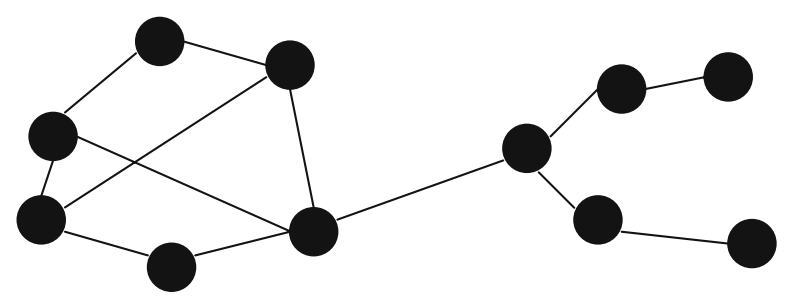

Fig. 2 Cyclic microstructures and dendritic structures in a network. The network members in the left hand of this network are part of a complex microstructure that provides multiple pathways by which an infection can be transmitted among any two members. On the right-hand, dendritic side of this network, however, there is only one path between two network members

virus can spread from an infected to an uninfected network member is greater, which tends to facilitate transmission. Friedman et al. (1997), (1999a, b) showed that HIV prevalence in injector networks was higher among members of a particular cyclic microstructure (the Seidman 2-core) in a large connected component of members than in the dendritic sections of this component or in smaller components.

Some sexual or injection risk relationships are anonymous or "quasi-anonymous" in that the partners know little or nothing about each other. In these circumstances, trying to collect locator information for a network study can be fruitless. Often, such relationships take place at events or locations that facilitate such contacts. Examples of such "quasi-anonymous risk nodes" include shooting galleries, gay bath-houses, and some group-sex events (Friedman et al., 2002a, b). In our Bushwick studies, we have collected data about a number of these quasi-anonymous risk nodes, including shooting galleries; sex and drug parties with large numbers of lesbian, gay, bisexual, and transgender participants; other parties where sex takes place; threesomes and foursomes; and "train bangs" in which only some participants know each other. Studies in Hartford, Connecticut, have shown that adding in consideration of shooting galleries provides linkages among Hispanic and African-American injection networks that otherwise appeared almost entirely separated (Weeks, Clair, \& Borgatti, 2000; Weeks, Clair, Borgatti, Radda, \& Schensul, 2002). Figure 3, taken from Friedman et al. 2002b, provides a schematic of how quasi-anonymous risk nodes can affect network connectivity. Figure 4 shows the distribution of people who have sex at group sex events in the same sample that Figure 1 displayed.

\section{Social Networks, Protection, and Vulnerability}

Little research has been conducted on the relationships of sociometric network location or of personal network

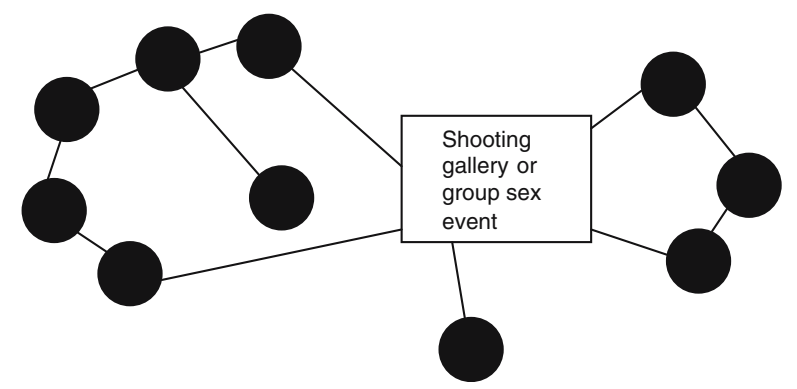

Fig. 3 Quasi-anonymous risk nodes and a network: what would otherwise be disconnected dendritic structure might be converted to a large cyclical microstructure by attendance at an anonymous group sex event. This could greatly affect the probability of HIV spreading between otherwise-disconnected parts of a community

characteristics (such as network size or the nature of network ties) to norms or to behavior. As has been discussed in a vast literature, norms are related to behavior.

In our previous study of the networks of injection drug users, we have shown that the same tightly-connected sections (Seidman 2-cores) of the large connected risk network component in which participants who have been exposed to HIV and hepatitis B are concentrated are places where risk behaviors are highest but also where people are most likely to provide others with HIV prevention messages and supplies (Curtis et al., 1995; Friedman et al., 1999a, b).

In a study of a high-risk, primarily drug-using population in Baltimore, Latkin, Sherman, and Knowlton (2003) found that the size of health-advice and financial-support networks were positively related to friends' norms promoting condom use; and that such norms were related to the reported condom use by the participants.

In our current NNAHRAY study, our data concern risk networks rather than social networks. Furthermore, we have not yet conducted statistical analyses focusing on the network-predictors of participants' peer norms or internal norms in these data. What we have done is to study participants' urging other people to engage in health-promoting action such as condom use, syringe exchange (if they inject drugs) and entry into treatment (if they use drugs). We have shown that these "intravention" behaviors are widespread among community residents, including among both drug users and nonusers (Friedman et al., 2004; 2005). Such intravention is also, we have argued, the "flip side of norms"-i.e., we suggest that intravention communication produces the messages that people have in mind when they say that their friends encourage or discourage certain behaviors. 
Fig. 4 Sex at Group Sex Party by Gender/Sexuality (MSM = up triangle, $\mathrm{WSW}=$ down triangle, other female $=$ circle, other male $=$ square) by Hardest Drug Use Ever (from dark red to light pink: IDU, Crack, NI Heroin or Cocaine; blue $=$ other) by Link Type (sex $=$ yellow line, IDU $=$ red, sex and IDU $=$ blue)

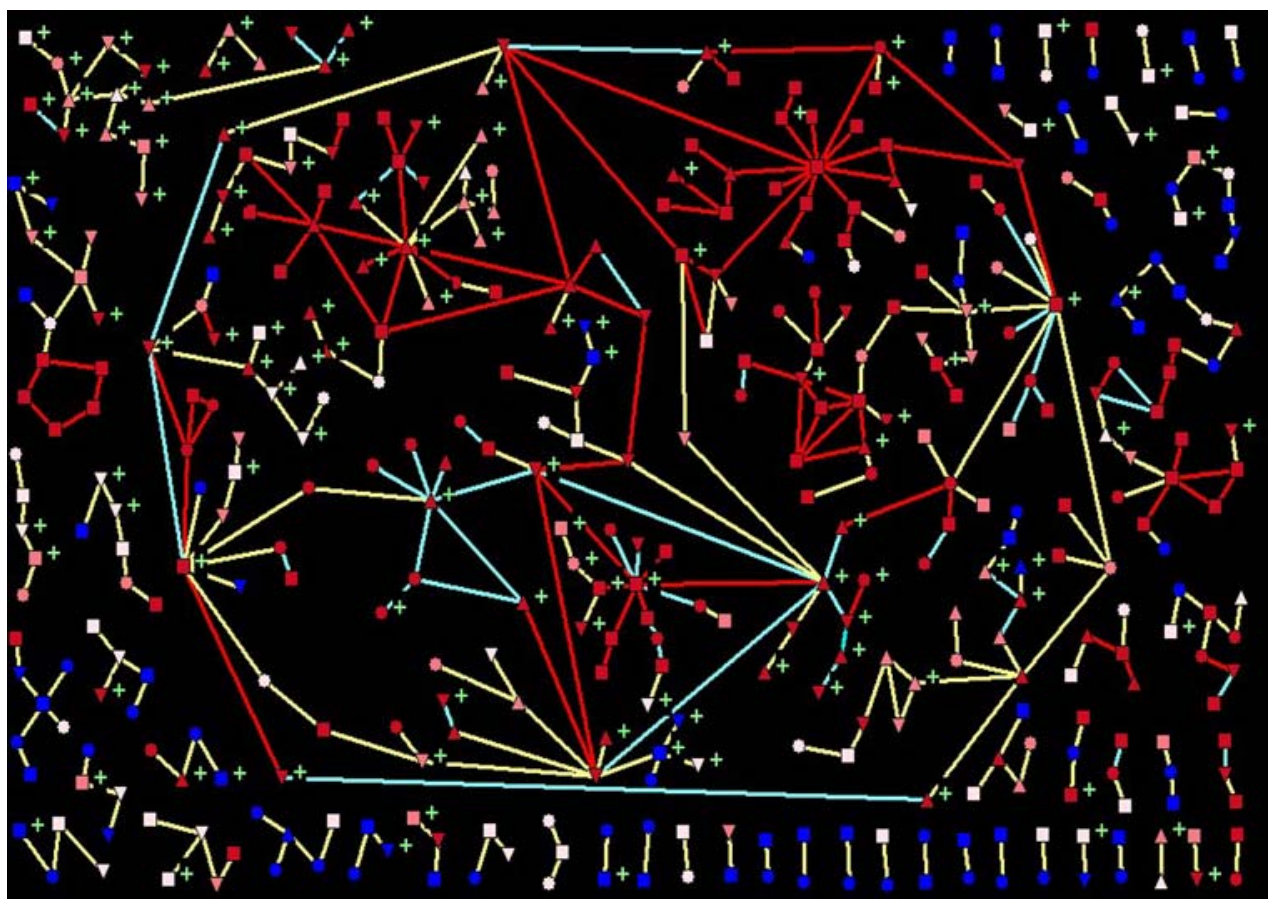

Intravention is widespread in the risk networks of the Bushwick community. This is seen in Fig. 5, which displays which participants in the NNAHRAY study were "star urgers"-i. e., participants who reported engaging in five or more of the seven kinds of intravention behaviors we asked about. In addition to the presence of star urgers in many parts of the community, such health communicators seem to be concentrated in at least some portions of the network where infection with HIV, herpesvirus type 2 and hepatitis C are concentrated.

What Shapes Networks and their Associated Norms, Intraventions, Practices, and Behaviors?

In a previous study of injection drug users' networks, we found that IDUs had considerable proportions of short-term ( $<1$ year), stable, and very stable ( 5 years or more) sexual and injection relationships (Friedman, 1996; Friedman et al., 1999a, b). In the NNAHRAY study, we found that the duration of sexual relationships varied by participant's age and also by participant's drug use (see Table 1), with the proportion of relationships that had lasted more than 5 years being low.

Given prior work that shows that networks seem to affect HIV transmission as well as risk behaviors and practices, remarkably little longitudinal research has been conducted in at-risk populations concerning what shapes changes in networks and, in term, how these changes in networks are related to changes in intra- vention, norms, risk practices, risk behaviors, or rates of HIV transmission. A recent dissertation by Elizabeth Costenbader provides extremely valuable first glimpses of the power of such research (Costenbader, 2005; Costenbader, Latkin, \& Astone, 2006 Forthcoming). She studied changes in the egocentric risk networks and social networks of IDUs and other highrisk drug users enrolled in the SHIELD study in Baltimore (Latkin, Forman, Knowlton, \& Sherman, 2003; Latkin et al., 2003). She confirms with these longitudinal data that there is indeed both considerable stability and, as well, considerable dynamism, in the social and risk relationships of drug users. Drug use patterns, notably, are not predictors of changes in networks. Insecure housing (becoming or remaining homeless), moving from one residence to another, as well as mental health problems like depression do predict unstable networks. Among these drug users, employment is associated with increased rather than decreased instability in networks.

At the relationship level, relationships with more trust, more daily interaction, and in which emotional support is provided are more likely to persist over time. Women's relationships are more likely to be stable than relationships between women and men or between men.

Changes in personal relationships in this study are related to changes in risky injection behavior. An IDU is particularly likely to increase her or his injection risk behavior if she or he acquires new drug-using network members. 
Fig. 5 Star Urgers by Gender/Sexuality (MSM = up triangle, $\mathrm{WSW}=$ down triangle, other female $=$ circle, other male $=$ square) by Hardest Drug Use Ever (from dark red to light pink: IDU, Crack, NI Heroin or Cocaine; blue $=$ other) by Link Type $($ sex $=$ yellow line, IDU $=$ red, sex and IDU $=$ blue)

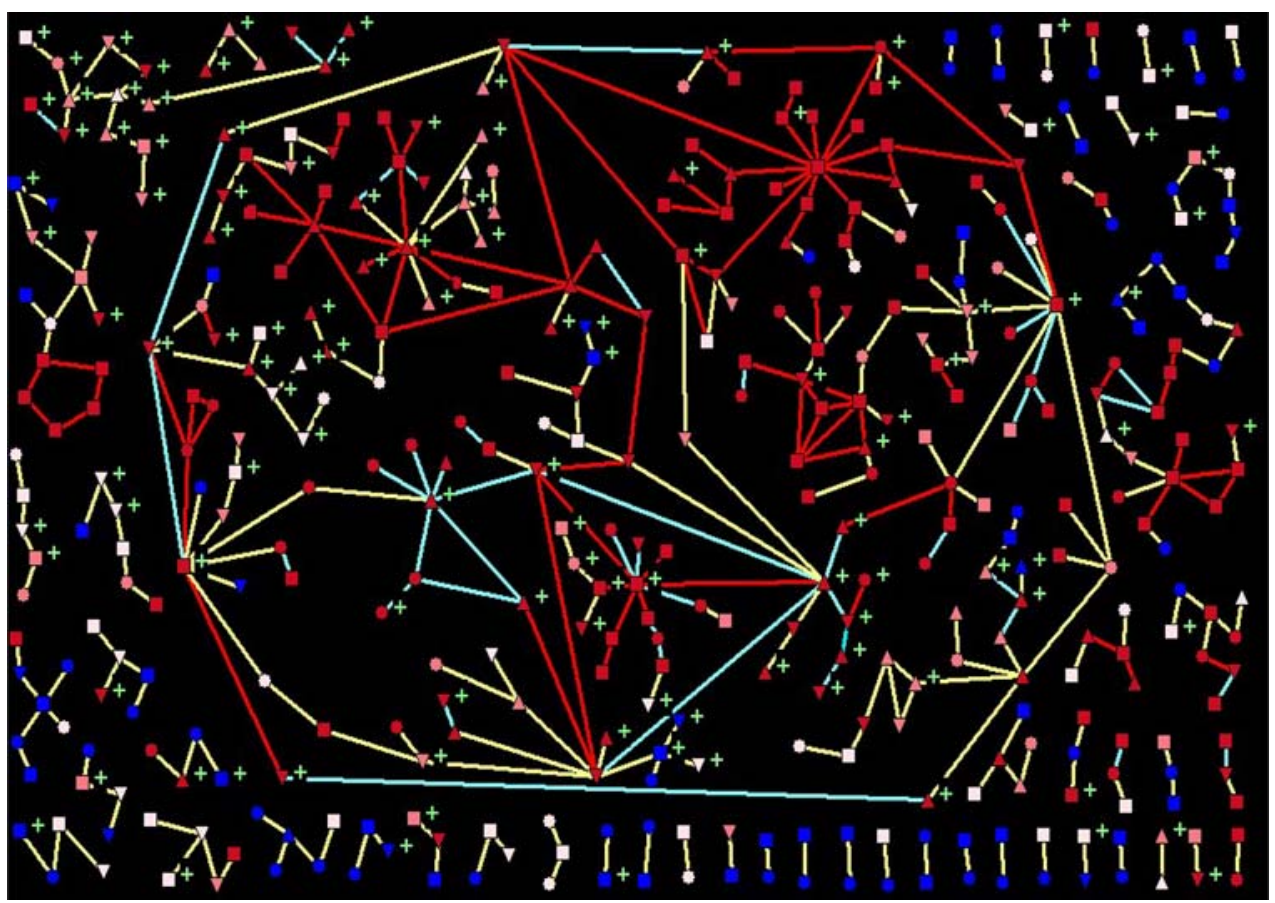

Table 1 Duration of sexual relationships by drug use of participant for 506 relationships of participants 25 years old or older and 267 relationships of participants $18-24$ years old

\begin{tabular}{|c|c|c|c|c|c|c|}
\hline \multirow[t]{2}{*}{ Duration of relationship } & \multicolumn{5}{|c|}{ "Hardest" drug used in last 3 months } & \multirow[t]{2}{*}{ Total } \\
\hline & No drug use & Marijuana & Non-injected heroin or cocaine & Crack & $\begin{array}{l}\text { Injection } \\
\text { drug use }\end{array}$ & \\
\hline \multicolumn{7}{|l|}{ Age $18-24$ years old } \\
\hline$N$ & 51 & 89 & 75 & 14 & 38 & 267 \\
\hline Less than 1 year $(\%)$ & 49 & 43 & 57 & 64 & 74 & 54 \\
\hline $1-5$ years $(\%)$ & 43 & 49 & 32 & 36 & 24 & 39 \\
\hline More than 5 years (\%) & 8 & 8 & 11 & 0 & 3 & 7 \\
\hline \multicolumn{7}{|l|}{$\begin{array}{l}\mathrm{P} \text { by } \chi^{2} \text {-test for trend } 0.0049 \\
\text { Age } 25 \text { years old or more }\end{array}$} \\
\hline$N$ & 43 & 41 & 94 & 128 & 200 & 506 \\
\hline Less than 1 year $(\%)$ & 26 & 34 & 40 & 44 & 47 & 42 \\
\hline $1-5$ years $(\%)$ & 53 & 41 & 30 & 37 & 35 & 36 \\
\hline More than 5 years $(\%)$ & 21 & 24 & 30 & 20 & 19 & 22 \\
\hline $\mathrm{P}$ by $\chi^{2}$-test for trend 0.0137 & & & & & & \\
\hline
\end{tabular}

The importance of Costenbader's research is clear. What should be equally clear is the importance of extending this research into additional populations such as gay men, sex workers, and youth in countries where sexual or other transmission is occurring rapidly. Such research should incorporate changes in norms and in intravention behaviors as fundamental parts of the causal chains being investigated; and, to the extent possible, should attempt to study sociometric social and risk networks as well as egocentric ones. Thus, we can conclude that Costenbader has opened up an area for research that can greatly benefit public health.

Another set of issues that shapes risk networks and mixing patterns is the prevalence and extent of attendance at quasi-anonymous risk nodes like group sex events, bath houses, and shooting galleries. Insofar as we are aware, almost no research has been done on this issue at the level of the community, city or metropolitan area. Clearly, this is another important area for research-that is, to determine the causes of, 
epidemiologic impacts of, and methods to intervene to affect the prevalence, size and distribution of such quasi-anonymous risk nodes.

Impacts of "Big events" on Networks and thence on HIV

As we and others have previously argued (Aral, 2002; Friedman et al., in press; Friedman \& Reid, 2002; Hankins, Friedman, Zafar, \& Strathdee, 2002), "big events" like wars, sociopolitical transitions, economic collapses, or ecological disasters can disrupt both social networks and risk networks, as well as the normative influence and the practical assistance that they can provide. These disruptions, in turn, can lead to outbreaks of HIV and other diseases. On the other hand, as Gisselquist (2005) and Spiegel (2004) have suggested, many African wars have not increased HIV transmission, and the case of the Philippines shows that transitions need not lead to outbreaks either. Gisselquist argues that the wars he studied may have reduced the extent of travel and thus the range and turnover in sexual risk networks, and that this may have provided protection against HIV outbreaks occurring. Again, little empirical research has been done on how "big events" affect risk networks, social networks, and their associated intraventions, normative regulation, and risk practices and behaviors, nor on how sociocultural contexts may mediate such effects. Such research is clearly important, as is research on how those caught up in such events can act so as to protect themselves and others and on how outsiders can assist them.

\section{Musings about New Approaches to Interventions} Based on Network Theory and Research

A number of successful interventions have been based on network ideas. These include the Indigenous Leader Outreach Model of recruiting people who are influential in drug users' networks to provide risk reduction education, persuasion and supplies to their network members (Wiebel et al., 1996); the SHIELD model of recruiting and training members of drug users' networks to be effective intervention agents (Latkin, Hua, \& Deavey, 2004; Latkin et al., 2003); and also the closely-related Peer Leader Intervention Model (which was originated as an intervention for gay men, but has been applied to adolescents in housing projects and many other at-risk populations), which uses peer leaders as determined by sociometric methods to influence their friends towards safer behavior; this model is sometime supplemented by having the peer leaders organize a local committee or committees to plan AIDS risk reduction activities and to put out small publications with this focus (Amirkhanian et al., 2005; Kelly, 2004; Sikkema et al., 2005).

Secondary syringe exchange is a diffusion-based approach to network intervention. In this model, drug injectors distribute syringes to members of their networks, and also collect used syringes from network members to return to syringe exchange sites. As Snead et al. (2003) report, since secondary syringe exchange is embedded in users' social networks, this makes it easy for peer education to take place. Users who provide syringes to others reported they took part because they wanted to help other IDUs; recipients took part because it was convenient to do so.

In many Latin-American countries there is broad experience with community based interventions where consideration of the political process, the history and the participation of the different social organizations were very much influenced by the popular education model of the Brazilian Paulo Freire or the social psychology of the Argentinean Enrique Pichon Riviere (Rossi et al., 2003; Vivas, Radulich, \& Bruno, 2003). Changes in social conditions were targeted more than changes in individual behavior. Most of these projects were developed in the 1970s to intervene in different social problems, but they have also influenced AIDS prevention work.

Fragmentation of social organization is a characteristic consequence of the sociopolitical transition and economic collapse in countries like Argentina, but nevertheless AIDS prevention with drug users developed by NGOs has been based on many of those principles. These projects have sought to link peer education and Leader Outreach Models to the interests of local political organizations, religious groups and community groups. A more conscious use of social network theory as it is related to social movement development (Friedman, 1996; Tarrow, 1998) might help such projects expand their influence and thus their risk-reduction messages more effectively.

The interventions just described show some of the potential that network theory has for HIV-oriented interventions. Here, we want to close the paper by musing about possible additional ways in which network approaches might be applied to HIV prevention and care.

One possibility might be to extend some of the network approaches for HIV prevention to improving retention in and adherence to antiretroviral therapy. There is considerable evidence that adherence is positively related to general social support (Weaver et al., 2005), to serodiscordant partners' receiving training in communication and support around taking the 
medication (Remien et al., 2005), and to having social network members who support adherence (Remien et al., 2003). These findings suggest that interventions like the Indigenous Leader Model or others that recruit influential network members to promote adherence and retention might be worthwhile endeavors.

As discussed above, the structures of social networks and of related forms of mixing patterns (such as quasianonymous risk nodes) shape the extent to which communities are vulnerable to HIV spread. As of yet, unfortunately, we know relatively little about what community policies and structures predispose sexual or injection networks to take the highly-vulnerable form of large connected components composed mainly of cyclic microstructures rather than being composed of more and smaller dendritic components. We also know little about what predisposes the social networks in a community to have strong intravention activity and effective protective norms. We need to find out the answers to these questions. At that point, there may well be public health "structural interventions" (Blankenship, Friedman, Dworkin, \& Mantell, 2006; Friedman \& Knight, 2003) that take the form of pushing for policies or urban structures that predispose networks to be less vulnerable to HIV. We cannot know in advance, of course, whether such changes will be easy or hard to implement. One hypothesis might be, for example, that repressive laws and policing approaches to drug use predispose injectors' networks to be cyclic and make it difficult for them to be highly intraventionist around infection control due to their having to emphasize safety from arrest-and that this might underlie findings that repressiveness is associated with higher HIV prevalence among IDUs (see Friedman et al., 2006). If this hypothesis were to be confirmed, it might lead to a difficult-to-implement set of recommendations in terms of making the Drug War less repressive. Other possible findings, however, might be easier to enact.

Acknowledgments The authors would like to acknowledge support from US National Institute on Drug Abuse project R01 DA13128 (Networks, Norms, and HIV/STI Risk among Youth) and its supplement (Networks, Norms and Risk in Argentina's Social Turmoil); P30 DA11041 (Center for Drug Use and HIV Research) and Fogarty International Training and Research project D43 TW001037-06 (Mount Sinai New York State Argentina HIV Prevention).

\section{References}

Amirkhanian, Y., Kelly, J. A., Kabakchieva, E., Kirsanova, A.,Vassileva, S., Takacs, J., DiFranceisco, W., McAuliffe, T., Khoursine, R., \& Mocsonaki, L. (2005). A randomized social network HIV prevention trial with young men who have sex with men in Russia and Bulgaria. AIDS, 19(16), 1897-1905.

Aral, S. O. (2002). Determinants of STD epidemics: Implications for phase appropriate intervention strategies. Sexually Transmitted Infections, 78, 3-13.

Blankenship, K. M., Friedman, S. R., Dworkin, S., \& Mantell, J. E. (2006). Structural interventions: concepts, challenges and opportunities for research. Journal of Urban Health, 83, 59-72.

Costenbader, E. C. (2005). The dynamics of injection drug users' social networks. Unpublished doctoral dissertation. Baltimore: The Johns Hopkins University Bloomberg School of Public Health.

Costenbader, E. C., Latkin, C., \& Astone, N. (2006). The dynamics of injection drug users' personal networks and HIV risk behaviors. Addiction, 101(7), 1003-1013.

Curtis, R., Friedman, S. R., Neaigus, A., Jose, B., Goldstein, M., \& Ildefonso, G. (1995). Street-Level Drug Market Structure and HIV Risk. Social Networks, 17, 219-228.

Des Jarlais, D. C., Marmor, M., Perlis, T., Friedmann, P., Titus, S., Aviles, E., Deren, S., Torian, L. V., Glebatis, D., Murrill, C., Monterroso, E., \& Friedman, S. R. (2000). HIV incidence among injecting drug users in New York City, 1992 to 1997: Evidence for a declining epidemic. American Journal of Public Health, 90, 352-359.

Flom, P. L., Friedman, S. R., Kottiri, B. J., Neaigus, A., Curtis, R., Des Jarlais, D. C., Sandoval, M., \& Zenilman, J. M. (2001). Stigmatized drug use, sexual partner concurrency, and other sexual risk network and behavioral characteristics of 18-24 year old youth in a high-risk neighborhood. Sexually Transmitted Diseases, 28, 598-607.

Friedman, S. R. (1996). Theoretical bases for understanding drug users' organizations. International Journal of Drug Policy, 7 , 212-219.

Friedman, S. R., \& Knight, K. (2003). What is the role of structural interventions in HIV prevention? Fact Sheet 46. San Francisco: Center for AIDS Prevention Studies.

Friedman, S. R., \& Reid, G. (2002). The need for dialectical models as shown in the response to the HIV/AIDS epidemic. International Journal of Sociology and Social Policy, 22, 177-200.

Friedman, S. R., Neaigus, A., Jose, B., Curtis, R., Goldstein, M., Ildefonso, G., Rothenberg, R. B., \& Des Jarlais, D. C. (1997). Sociometric Risk Networks and HIV Risk. American Journal of Public Health, 87(8), 1289-1296.

Friedman, S. R., Curtis, R., Neaigus, A., Jose, B., \& Des Jarlais, D. C. (1999a). Social networks, drug injectors' lives, and HIV/AIDS. New York: Kluwer/Plenum.

Friedman, S. R., Neaigus, A., Jose, B., Curtis, R., Ildefonso, G., Goldstein, M., \& Des Jarlais D. C. (1999b). Networks, Norms, and Solidaristic/Altruistic Action against AIDS among the Demonized. Sociological Focus, 32, 127-142.

Friedman, S. R., Jose, B., Neaigus, A., Curtis, R., Vermund, S. H., \& Des Jarlais, D. C. (2000). Network-related mechanisms may help explain long-term HIV-1-seroprevalence levels that remain high but do not approach populationgroup saturation. American Journal of Epidemiology, 152(10), 913-922.

Friedman, S. R., Flom, P. L., Kottiri, B. J., Neaigus, A., Sandoval, M., Curtis, R., Zenilman, J. M., \& Des Jarlais, D. C. (2001). Prevalence and correlates of anal sex with men among young adult women in an inner city minority neighborhood. AIDS, 15, 2057-2060.

Friedman, S. R., Flom, P. L., Kottiri, B. J., Sandoval, M., Neaigus, A., Maslow, C., Mateu-Gelabert, P., Zenilman, J., Des Jarlais, D. C., \& Barth-Jones, D. C. (2002a). Networks, 
norms and HIV risk in New York City. In: The network paradigm in research on drug abuse, HIV, and other bloodborne and sexually transmitted infections: New perspectives, approaches, and applications, meeting proceedings (pp. 4149). National Institute on Drug Abuse.

Friedman, S. R., Neaigus, A., Sandoval, M., Mateu-Gelabert, P., Flom, P., Kottiri, B. J., et al. (2002b). What risk networks and social networks can contribute to understanding and preventing the potential spread of HIV. 2001 Global research network meeting on HIV prevention in drug-using populations. Fourth annual meeting report. Melbourne, Australia.

Friedman, S. R., Flom, P. L., Kottiri, B. J., Neaigus, A., Sandoval, M., Fuld, J., Curtis, R., Zenilman, J. M., \& Des Jarlais, D. C. (2002c). Consistent condom use among drug-using youth in a high-HIV-risk neighborhood. AIDS Care, 14, 493-507.

Friedman, S. R., Flom, P. L., Kottiri, B. J., Zenilman, J. M., Curtis, R., Neaigus, A., Sandoval, M., Quinn, T., \& Des Jarlais, D. C. (2003a). Drug use patterns and infection with sexually transmissible agents among young adults in a highrisk neighborhood in New York City. Addiction, 98, 159169.

Friedman, S. R., Ompad, D. C., Maslow, C., Young, R., Case, P., Hudson, S. M., Diaz, T., Morse, E., Bailey, S., Des Jarlais, D. C., Perlis, T., Hollibaugh, A., \& Garfein, R. S. (2003b). HIV prevalence, risk behaviors, and high-risk sexual and injection networks among young women injectors who have sex with women. American Journal of Public Health, 93, 902-906.

Friedman, S. R., Maslow, C., Bolyard, M., Sandoval, M., MateuGelabert, P., \& Neaigus, A. (2004). Urging others to be healthy: "Intravention" by injection drug users as a community prevention goal. AIDS Education and Prevention, 16, 250-263.

Friedman, S. R., Bolyard, M., Maslow, C., Mateu-Gelabert, P., \& Sandoval, M. (2005). Networks, risk-reduction communication, and norms., Focus, 20(January), 5-6.

Friedman, S. R., Cooper, H. L. F., Tempalski, B., Keem, M., Friedman, R., Flom, P. L., \& Des Jarlais, D. C. (2006). Relationships of deterrence and law enforcement to drugrelated harms among drug injectors in U.S.A. metropolitan areas, AIDS, 20, 93-99.

Friedman, S. R., Kippax, S. C., Phaswana-Mafuya, N., Rossi, D., \& Newman, C. E. (2006). Emerging future issues in HIV/ AIDS Social Research. AIDS, 20, 959-965.

Gisselquist, D. (2005). Impact of long-term civil disorders and wars on the trajectory of HIV epidemics in sub-Saharan Africa. Journal of Social Aspects of HIV/AIDS Research Alliance, 1, 114-127.

Gorbach, P., Drumright, L., \& Holmes, K. (2005). Discord, discordance, and concurrency: Comparing individual and partnership-level analyses of new partnerships of young adults at risk of sexually transmitted infections. Sexually Transmitted Diseases, 32(1), 7-12.

Hankins, C., Friedman, S. R., Zafar, T., \& Strathdee, S. (2002). Transmission and prevention of HIV and STD in war settings: implications for current and future armed conflicts. AIDS, 16, 2245-2252.

Kelly, J. A. (2004). Popular opinion leaders and HIV prevention peer education: Resolving discrepant findings, and implications for the development of effective community programmes. AIDS Care, 16(2), 139-150.

Kretzschmar, M., \& Morris, M. (1996). Measures of concurrency in networks and the spread of infectious disease. Math and Bioscience, 15, 133(2), 165-195.
Latkin, C. A., Sherman, S., \& Knowlton, A. (2003). HIV prevention among drug users: outcome of a network-oriented peer outreach intervention. Health Psychology, 22(4), 332339.

Latkin, C. A., Forman, V., Knowlton, A., \& Sherman, S. (2003) Norms, social networks, and HIV-related risk behaviors among urban disadvantaged drug users. Social Science and Medicine, 56, 465-476.

Latkin, C. A., Hua, W., \& Davey, M. A. (2004). Factors associated with peer HIV prevention outreach in drug-using communities. AIDS Education and Prevention, 16(6), 499508.

Manhart, L. E., Aral, S. O., Holmes, K. K., \& Foxman, B. (2002). Sex partner concurrency: measurement, prevalence, and correlates among urban 18-39-year-olds. Sexually Transmitted Diseases, 29(3), 133-143.

Potterat, J. J., Muth, S. Q., Rothenberg, R. B., ZimmermanRogers, H., Green, D. L., Taylor, J. E., Bonney, M. S., \& White, H. A. (2002). Sexual network structure as an indicator of epidemic phase. Sexually Transmitted Infections, 78, 152-158.

Potterat, J. J., Zimmerman-Rogers, H., Muth, S. Q., Rothenberg, R. B., Green, D. L., Taylor J. E., Bonney, M. S., \& White, H. A. (1999a). Chlamydia transmission: Concurrency, reproduction number, and the epidemic trajectory. American Journal of Epidemiology, 150, 1331-1339.

Potterat, J. J., \& Rothenberg, R. B. (1999b). Network structural dynamics and infectious disease propagation. International Journal of STD and AIDS, 10, 182-185.

Remien, R. H., Stirratt, M., Dolezal, C., Dognin, J., Wagner, G., Carballo-Dieguez, A., El-Bassel, N., \& Jung, T. (2005). Couple-focused support to improve HIV medication adherence: A randomized controlled trial. AIDS, 19, 807814.

Remien, R. H., Hirky, E., Johnson, M., Weinhardt, L., Whittier, D., \& Giang M. (2003). Adherence to medication treatment: a qualitative study of facilitators and barriers among a diverse sample of HIV+ men and women in four U.S. cities. AIDS and Behavior, 7, 61-72.

Rossi, D., Goltzman, P., Cymerman, P., Touze, G., \& Weissenbacher, M. (2003). Human immunodeficiency virus/acquired immunodeficiency syndrome prevention in injection drug users and their partners and children: Lessons learned in latin America-the Argentinean case. Clinical Infectious Diseases, 37, S362-S365.

Sikkema, K. J., Anderson, E., Kelly, J. A., Winett, R.,GoreFelton, C., Roffman, R., Heckman, T., Graves, K., Hoffmann, R., \& Brondino, M. J. (2005). Outcomes of a randomized, controlled community-level HIV prevention intervention for adolescents in low-income housing developments. AIDS, 19(14), 1509-1516.

Snead, J., Downing, M., Lorvick, J., Garcia, B., Thawley, R., Kegeles, S., \& Edlin, B. R. (2003). Secondary syringe exchange among injection drug users. Journal of Urban Health, 80, 330-348.

Spiegel, P. B. (2004). HIV/AIDS among conflict-affected and displaced populations: Dispelling myths and taking action. Disasters, 28, 322-339.

Tarrow, S. (1998). Power in movement: Social movements and contentious politics (2nd ed.). Cambridge: Cambridge University Press.

Vivas, L., Radulich, G., \& Bruno, D. (2003). Vulnerable among the vulnerable: Drug users in situations of poverty and indigence in Argentina. Clinical Infectious Diseases, 37, S358-S361. 
Weaver, K. E., Llabre, M., Durán, R., Antoni, M., Ironson, G., Penedo, F., \& Schneiderman, N. (2005). A stress and coping model of medication adherence and viral load in HIV-positive men and women on highly active antiretroviral therapy (HAART). Health Psychology, 24, 385-392.

Weeks, M. R., Clair, S., \& Borgatti, S. P. (2000, April). High-risk sites and drug user social networks: Linkages for HIV transmission. Paper presented at the 20th Annual Sunbelt International Social Network Conference. Vancouver, BC, Canada.

Weeks, M., Clair, S., Borgatti, S., Radda, K., \& Schensul, J. (2002). Social networks of drug users in high risk sites: Finding the connections. AIDS and Behavior, 6, 193-206.
Wiebel, W. W., Jimenez, A., Johnson, W., Ouellet, L., Jovanovic, B., Lampinen, T., Murray, J., \& O’Brien, M. U. (1996). Risk behavior and HIV seroincidence among out-of-treatment injection drug users: A four-year prospective study. Journal of Acquired Immune Deficiency Syndromes and Human Retrovirology, 12, 282-289.

Young, R. M., Friedman, S. R., Case, P., Asencio, M., \& Clatts, M. (2000). Women injection drug users who have sex with women exhibit increased infection and risk behaviors. Journal of Drug Issues, 30, 499-524. 